\title{
A new record of the genus Sperchon (Acari: Hydrachnidia, Sperchontidae) from Turkey
}

\section{Yunus ESEN (D)}

\author{
Solhan Vocational School of Health Services, Bingöl University, Bingöl, Turkey \\ e-mail: yesen@bingol.edu.tr
}

Received: 13 January 2021

Accepted: 25 January 2021

Available online: 27 January 2021

ABSTRACT: A new water mite Sperchon (Hispidosperhcon) beckeri Bader and Sepasgosarian, 1984 is recorded for the first time from Elazığ province, Turkey. This species is characterized by the P-2 with long finger-shaped ventral projection and P-4 with well-developed ventral tubercles.

Keywords: Mite, Sperchon, new report, Elazı̆̆, running water.

Zoobank: http://zoobank.org/01ADDFFC-87BB-4A67-9780-1CFF756BCC02

Water mites of the genus Sperchon Kramer, 1877 have been found in all biogeographic regions except for Australia and Antarctica. It is widely distributed in the Holarctic, Oriental and Ethiopian regions (Cook, 1974).

Up to now, only 19 species belong to the genus have been described from Turkey (Erman et al., 2010, 2019; Esen et al., 2010): During a survey of the freshwater fauna of Eastern Turkey (Elaziğ Province), one new record of the water mite genus Sperchon Kramer was detected from running waters. The aim of this paper is to contribute sperchontid water mites in Turkey.

Samples were collected by hand netting, sorted on the spot from the living material, fixed in Koenike's fluid and dissected as described elsewhere (e.g. Gerecke et al., 2007). The specimens are deposited in the research collection of the Biology Department, Bingöl University, Bingöl, Turkey.

The composition of the material is given as: (males/females/deutonymphs). All measurements are given in $\mu \mathrm{m}$. The following abbreviations are used: Ac-1 = first acetabulum, $\mathrm{Cx}-\mathrm{I}=$ first coxae, $\mathrm{Cxgl}-4=$ coxoglandulare 4, dc-1-4 = dorsocentralia 1-4, dl-1-7 = dorsoglandularia $1-7, \mathrm{dL}=$ dorsal length, $\mathrm{L}=$ length, $\mathrm{W}=$ width, $\% \mathrm{~L}=$ relative length, I-Leg-6 = Leg 1 , sixth segment (tarsus), P$1=$ palp, first segment.

Family Sperchontidae Thor, 1900

Genus Sperchon Kramer, 1877

Sperchon (Hispidosperchon) beckeri Bader and Sepasgosarian, 1984 (Figures 1-3)

Specimens examined. Elazı̆̆ province (Turkey), Alacakaya district, Halkalı Village, spring and low order streams, 38³2'44" N, 3956'22" E, 1507 m a.s.l., 23.08.2020, (2/3/0); Elazı̆g province (Turkey), Arıcak district, Akdağlar mountain, low order streams, 38³7'56" N, $40^{\circ} 08^{\prime} 00^{\prime \prime}$ E, $2145 \mathrm{~m}$ a.s.l., 05.07.2018, (4/8/1). One male was dissected and slide-mounted in Hoyer's fluid.
Diagnosis. Integument ventrocaudally with fine denticles arranged in hexagonal pattern, dorsum with six pair and one medially muschle attachment plates. Cx-I+II medially not fused, Cx-III without coxoglandularia. Excretory pore smooth. Capitulum with short rostrum, P-2 with welldeveloped finger-shaped ventrodistal projection; P-4 shorter than P-3, with two well developed ventral tubercles close to each other, each bearing peg-like and at the tip rounded setae, the proximal tubercle larger, located in the centre of the segment, the distal one minor, located in the distal part.

Description. Integument dorsally and ventrally with fine denticles arranged in a hexagonal pattern (Fig. 3C); these denticles laterally and caudally inflating to form small rounded papillae; these papillae regularly-arranged, in juveniles these papillae covered whole of dorsal surface (Fig. 3A). Dorsum with six pairs and one medially muscle attachment plates both males and females (Fig. 1A). Ventral view of $\mathrm{Cx}-\mathrm{I}+\mathrm{II}$ medially close to each other, but not fused (Fig. 1B). Cx-III without a medial glandular opening (Cxgl-4). Ac-1-2 longish, Ac-3 round. Posterior part of the venter with a small unpaired postgenital platelet. Excretory pore smooth. Capitulum (Fig. 3D) with short rostrum; palps (Figs 1C-D, 2A, 3D); P-1 without dorsal seta; P-2 distoventrally with a long projection at its tip bearing three fine setae, one long and two short; dorsally bearing about 18-20 stout setae, some of them plumose. P-3 bearing about 12 stout setae and 10 fine setae, all restricted to the dorsal part; P-4 shorter than P-3, with the two well developed ventral tubercles close to each other, each bearing peg-like, at the tip rounded setae, the proximal one larger, located in the centre of the segment, the distal one larger, located in the distal part; P-5 short, with strong distal claws; Leg segments slender, III-/IV-L with a few short, simple dorsal setae; ambulacrum with claw blade well protruding, bearing a long dorsal and a shorter ventral clawlet (Fig. 1F).

Male (n=3): Idiosoma L 552-770, W 489-661; distance between posterior edge of Cx-IV 432-533. Genital valves $\mathrm{L}$ 138-207, pregenital sclerite forming an acute triangle; $\mathrm{L}$ Ac-1-3 50-63, 55-80, 43-57; Capitulum L 202-321; chelicera (Fig. 1E) L 198-310, basal segment L 126-240 claw L 
55-70, L ratio chelicerae basal segment/claw 3.42-3.60; palp (Figs 1 C,D) total L 443-577, dL: P-1, 20-22; P-2, 108124; P-3, 139-196; P-4, 135-188; P-5, 37-47; \%L: P-1, 3.84.5; P-2, 24.4-21.5; P-3, 31.4-34.0; P-4, 30.5-32.6; P-5, 8.18.6; P-2/P-4 ratio 0.7-0.8. Leg segments L: I-Leg- 1-6: 6075, 62-80, 93-112, 138-179, 132-158, 120-146; IV-Leg-16: 102-145, 106-134, 122-153, 237-298, 230-288, $207-$ 224.

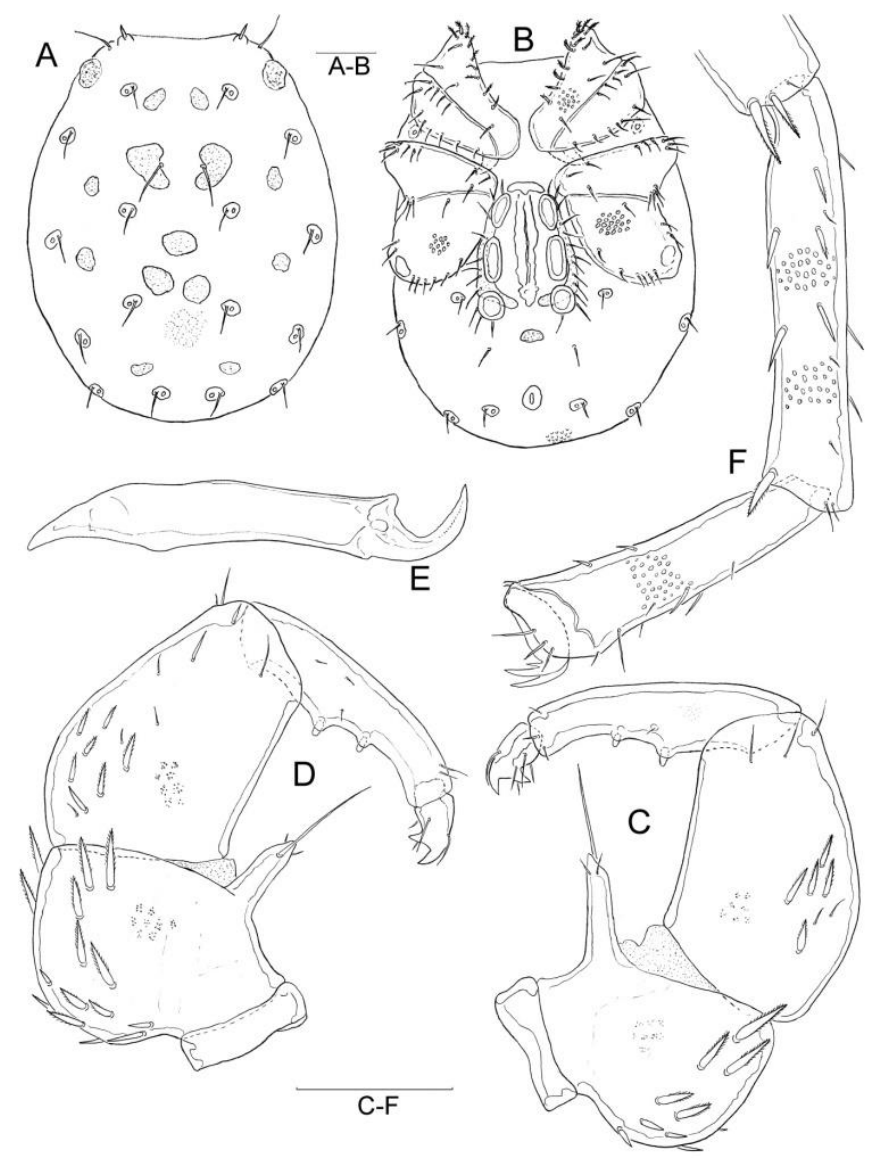

Figure 1. Sperchon beckeri (Male) - A. Idiosoma, dorsal view, B. Idiosoma, ventral view, C. Palp, medial view, D. Palp, lateral view, E. Chelicera, F. IV-L-5-6 (Scale bars= $100 \mu \mathrm{m})$.

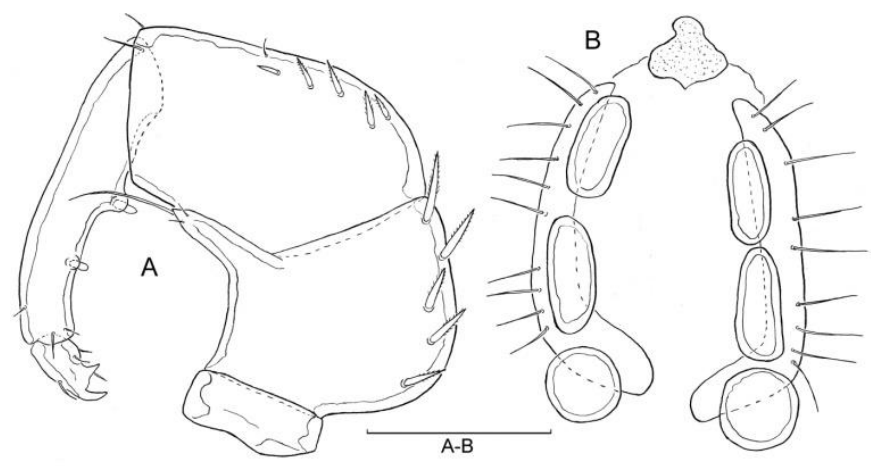

Figure 2. Sperchon beckeri (Female) - A. Palp, medial view, B. Genital field (Scale bar $=100 \mu \mathrm{m}$ ).

Female (n=3): Idiosoma L 942-1490, W 670-1145; distance between posterior edge of Cx-IV 520-685. Genital valves (Fig. 2B) L 180-246; pregenital sclerite forming a drop shaped; L Ac 1-3 51-68, 55-97, 48-67. Capitulum L 230-291; chelicera L 226-298, basal segment L 160-216, claw L 66-82, L ratio chelicerae basal segment/claw 2.422.63; palp (Fig. 2A) total L 440-612 dL and \%L (in parentheses): P-1, 22-30 (5.0); P-2, 110-149 (24.3-25.0); P-3, 140-204 (31.8-33.3); P-4, 132-182 (29.7-30.0); P-5, 36-54 (8.2-8.8); P-2/P-4 ratio 0.8. Leg segments L: I-Leg-1-6: 6872, 80-83, 95-109, 152-173, 147-156, 140-160; IV-Leg-16: $121-141,120-135,140-164,267-302,250-280,211$ 242.
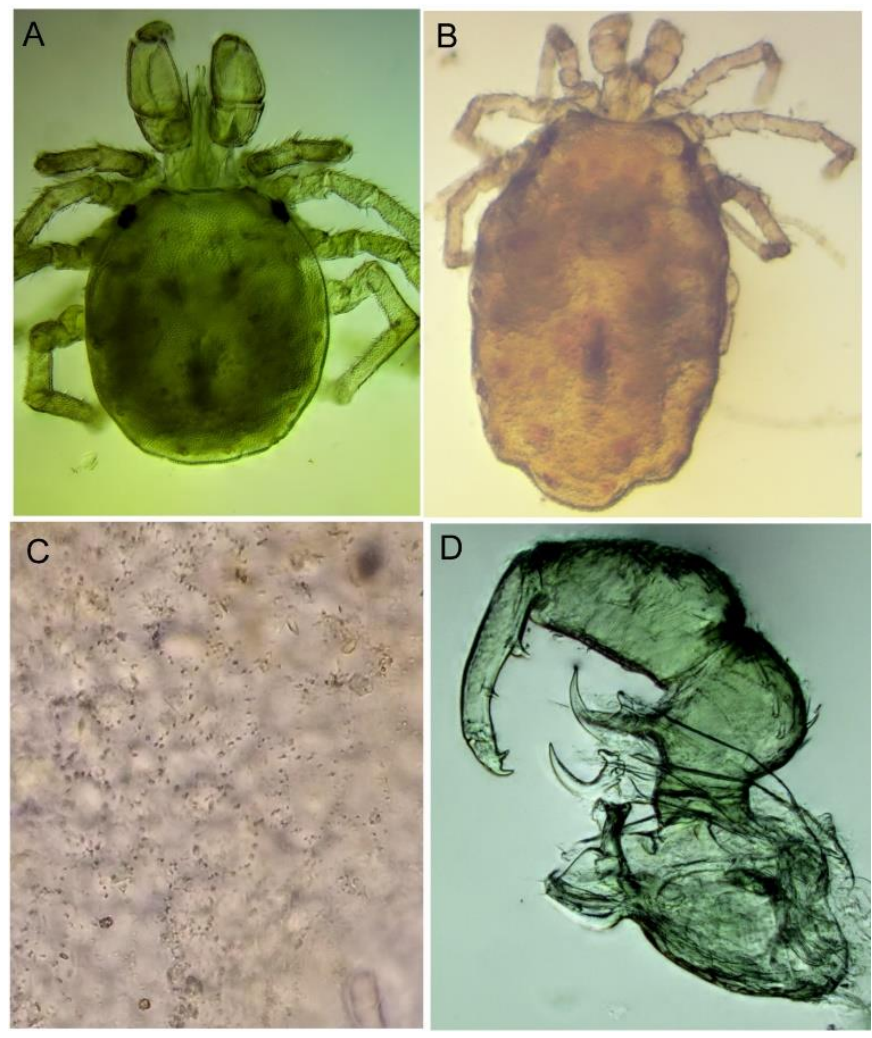

Figure 3. Sperchon becheri, (A, male; B-D, female) - A. Dorsal view, B. Dorsal view, C. Integument, ventrally, D. Gnathosoma (No scale bar).

Habitat. Low order streams, running waters near the springs, in the moss vegetation.

Distribution. Known from Iran (Mazaran and Karaj) (Bader and Sepasgosarian, 1984; Pešić et al., 2004) and Turkey (Elazığ) (current study).

Discussion. Having reticulated integument both dorsal and ventral side, absence of coxoglandularia of CX-III, P-2 with long finger-shaped ventral projection and P-4 with well developed ventral tubercles our specimens agreed with original description of the species Sperchon beckeri Bader \& Sepasgosarian, 1984. However, the Turkish specimens are different by the third pair of genital acetabula rounded (the third pair of genital acetabula more or less triangular). Pešić et al. (2004) recorded the species second time from Mazandaran Province after its original description (Bader and Sepasgosarian, 1984). This is third record of this species after above mentioned records from Iran. 


\section{Statement of ethics approval}

Not applicable.

\section{Funding}

There is no fund for the present study.

\section{Conflict of interest}

No potential conflict of interest was reported by the author.

\section{REFERENCES}

Bader, C. and Sepasgozarian, H. 1984. Wassermilben (Acari, Prostigmata, Hydrachnellae) aus dem Iran. 15. Mitteilung: Sperchon (Mixosperchon) beckeri n. sp. Entomologische Mitteilungen aus dem Zoologischen Museum Hamburg 76 (120): 443-447. [In German]

Cook, D.R. 1974. Water mite genera and subgenera. Memoirs of the American Entomological Institute 21: 1860.

Erman, O., Gülle, P., Özkan, M., Candoğan, H. and Boyacı, Y.Ö. 2019. Checklist of the water mites (Acari: Hy- drachnidia) of Turkey: First supplement. Zootaxa, 4686 (3): 376-396.

doi: 10.11646/zootaxa.4686.3.4

Erman, O., Pešić, V., Esen, Y. and Özkan, M. 2010. A checklist of the water mites of Turkey (Acari: Hydrachnidia) with description of two new species. Zootaxa, 2624: 148.

doi: 10.11646/zootaxa.2624.1.1

Gerecke, R., Weigmann, G., Wohltmann, A. and Wurst, E. 2007. Order Acari - General introduction and key to major groups. In: Süßwasserfauna von Mitteleuropa. Vol. 7/2-1. Gerecke, R. (Ed.). Elsevier GmbN, Spektrum Akademischer Verlag, München, Germany, 14-57. doi: 10.1007/978-3-662-55958-1_2

Pešić, V., Saboori, A., Asadi, M. and Vafaei, R. 2004. New records of water mites (Acari, Hydrachnidia) from Iran, with the description of one new species. Zoology in the Middle East, 32: 97-110. doi: 10.1080/09397140.2004.10638051

\section{Edited by: Orhan Erman}

Reviewed by: Two anonymous referees

Citation: Esen, Y. 2021. A new record of the genus Sperchon (Acari: Hydrachnidia, Sperchontidae) from Turkey Acarological Studies, 3 (1): 48-50. 